Article

\title{
Effect of Heterogeneous Nucleation on Removal of Arsenic from Molten Steel by Rare Earth Addition
}

\author{
Hongpo Wang *, Peng Yu, Silu Jiang and Yu Wang * \\ College of Materials Science and Engineering, Chongqing University, Chongqing 400044, China; \\ 201931021027@cqu.edu.cn (P.Y.); 201809021093@cqu.edu.cn (S.J.) \\ * Correspondence: wanghp@cqu.edu.cn (H.W.); wangyu@cqu.edu.cn (Y.W.); \\ Tel.: +86-183-2300-5236 (H.W.); +86-131-9319-4973 (Y.W.)
}

Received: 6 May 2020; Accepted: 18 May 2020; Published: 20 May 2020

\begin{abstract}
Cleanliness control is an eternal theme to improve the properties of steel products. With the increasing recycling rates of scrap steel, the removal and stabilization of residual elements have become a vital issue for improving the performance of steel products. Thermodynamic and mismatch calculations plus laboratory experiments were carried out to study the heterogeneous nucleation phenomena of inclusions when lanthanum was employed to remove arsenic from molten steel and stabilize arsenic in solid steel. The effect of heterogeneous nucleation on the mechanism of arsenic removal was discussed. A series of heterogeneous nucleation phenomena of inclusions in the La-O-S-As system were discovered, and the heterogeneous nucleation among the inclusions turned out to be selective. As the vital product of arsenic removal, La-S-As is most likely to generate with $\mathrm{LaS}$ as heterogeneous nucleation cores, and its possible chemical formula turned out to be 3LaS.LaAs. Sulfur plays an essential role in removing arsenic from molten steel by adding lanthanum. It needs to control the initial sulfur content in an appropriate range, because the high initial content causes too much loss of rare earth, and the low initial content cannot produce LaS and La-S-As.
\end{abstract}

Keywords: clean steel; rare earth; heterogeneous nucleation; inclusion; residual element

\section{Introduction}

The residual element arsenic is an essential factor that harms the quality and performance of steel products. The oxidation potential of arsenic is weaker than that of iron, and it is challenging to remove arsenic from steel in the steelmaking process. Arsenic prefers to enrich and form low melting point phases through solidification segregation and interface segregation [1-4], resulting in a decrease of hot workability and processability of steel [5]. In the 1990s, the average concentration of arsenic in 48 steel grades of five special steel mills in China reached $100 \mathrm{ppm}$, according to the statistical data derived from 303 heats of alloy steel [6]. The recycling of scrap steel makes arsenic continuously enriched in steel, and the increasing storage and utilization ratio of scrap steel exacerbate its enrichment. It is expected that the comprehensive utilization ratio of scrap steel will reach $80 \%$ by 2050 in China [7]. Having a massive amount of arsenic-bearing iron ore, China is under high pressure to deal with the problem caused by the enrichment of arsenic.

Steel companies generally adopt the method of mixing high-quality iron ore or molten iron with arsenic-containing raw materials to reduce arsenic concentration in steel products, which is unsustainable [8]. Therefore, researchers conducted arsenic removal experiments in the sintering, molten iron pretreatment, and refining processes. Sintering reduction [9], coal-based direct reduction [10], and microwave heating reduction [11] have been tried to remove arsenic from iron concentrates in the laboratory. Based on the reduction theory, using calcium to remove arsenic from molten steel is the focus of researchers. Pure calcium metal, various calcium alloys, combined with $\mathrm{CaF}_{2}$ slags, have 
been tried to remove arsenic from molten iron or steel [12-17]. However, the volatilization of calcium is severe owing to its high vapor pressure, making the effective calcium amount used for arsenic removal difficult to control; moreover, the residual calcium in steel can give rise to the formation of large spherical oxides, detrimental to the properties of steel products.

Rare earth (RE) elements have been used to react with arsenic to form high melting point compounds to remove arsenic from molten steel and to improve the existing state of arsenic in solid steel when arsenic concentration is not high $[2,3,5,18]$. It is noted that the arsenic compounds are not the first ones to generate in molten steel after RE additions; instead, the first ones are oxides, oxysulfides, and sulfides of RE [19-22]. RE does not react with arsenic until the concentrations of oxygen and sulfur decrease to a certain level [23], then RE-S-As can generate in molten steel [24,25]; further, a series of arsenic compounds, namely RE-As [3,18,26,27], RE-O-As [28], RE-S-As [29], and RE-O-S-As [28], can generate during the solidification and cooling processes. The thermodynamics and kinetics of the formation of arsenic RE compounds are fundamental issues in the study of using RE to remove and stabilize arsenic in steel.

This work focuses on the formation mechanism of arsenic RE compounds in molten steel. Combined with calculations and laboratory experiments, the effect of heterogeneous nucleation on the removal of arsenic from molten steel by adding RE element lanthanum was investigated.

\section{Materials and Methods}

The alloy preparation was carried out in the laboratory using a $15 \mathrm{~kW}$ induction furnace under the protection of $99.999 \%$ argon gas. About $550 \mathrm{~g}$ of high carbon steel rods without rust were used as the raw material and placed in an alumina crucible. Table 1 shows its chemical compositions [24]. After carrying out the process of evacuating and refilling with argon gas twice, the flow rate of argon gas was set to $0.8 \mathrm{~L} / \mathrm{min}$ for $10 \mathrm{~min}$ and changed to $0.3 \mathrm{~L} / \mathrm{min}$. Then we started heating by gradually increasing the output voltage of the induction furnace. A quartz tube with one head closed and several magnets were used to hold arsenic particles with a purity of $99.9 \%$ together with about $5 \mathrm{~g}$ steel rods, wrapped by high-purity iron sheets. They were added in molten steel after the raw material was melted for $10 \mathrm{~min}$ under $1600^{\circ} \mathrm{C}$. The arsenic addition was $0.020 \%$. After $30 \mathrm{~min}$, a sample was extracted directly from the molten steel using a quartz tube. Then lanthanum particles, held by the same method, were added in the same way. The lanthanum addition was $0.15 \%$. After 20 min, the induction furnace power was turned off, and the steel was cooled to room temperature in the furnace. More details of the sample preparation can be found in previous work [24].

Table 1. Chemical compositions of the raw material (mass\%).

\begin{tabular}{ccccccccc}
\hline Elements & $\mathbf{C}$ & $\mathbf{S i}$ & $\mathbf{M n}$ & $\mathbf{P}$ & $\mathbf{S}$ & Al & O & As \\
\hline Content & 0.79 & 0.21 & 0.61 & 0.011 & 0.015 & 0.001 & 0.0024 & 0.005 \\
\hline
\end{tabular}

A non-aqueous electrolytic method was employed to extract inclusions from the steel ingot to observe three-dimensional morphologies of the inclusions. The sample was used as the anode and a stainless-steel plate as the cathode. The sample with a diameter of $10 \mathrm{~mm}$ was taken at $1 / 2$ radius of the ingot with entire ingot height. The electrolyte consists of 1 vol. $\%$-methyl ammonium chloride, 5 vol.\% triethanolamine, 5 vol.\% glycerin, and 89 vol.\% methanol. A direct current (DC) power supply (PS-303DF, Shenzhen China) was used to offer a current density at the range of $60-90 \mathrm{~mA} / \mathrm{cm}^{2}$, and the electrolysis temperature was set to $0-3{ }^{\circ} \mathrm{C}$ by insulating with the ice-water mixture. Nitrogen gas was used to stir the electrolyte to promote the uniformity of its composition. The electrolysis time was $13 \mathrm{~h}$. After the electrolysis, the anode was placed in alcohol and ultrasonically cleaned for $5 \mathrm{~min}$ to make the inclusions enter the alcohol. After multiple magnetic separations and elutriations, the alcohol solution rich in inclusions was dried at room temperature. Then the inclusions were used for further investigation. 
Samples used for the composition measurement were taken the $1 / 2$ height and $1 / 2$ radius of the steel ingot. The initial and final concentrations of arsenic and lanthanum were measured with an inductively coupled plasma optical emission spectrometer (ICP-OES, Optima 8000, Waltham, MA, USA). A carbon-sulfur spectrometer (HCS-801S, Deyang, China) was used to measure the sulfur content. Inclusions were observed with an optical microscope (OM, Sunny XD30M, Ningbo, China) and a scanning electron microscope (SEM, JEOL 7800F, Tokyo, Japan). The compositions of inclusions were identified with an energy dispersive spectrometer (EDS, $80 \mathrm{~mm}^{2} \mathrm{X}-\mathrm{Max}^{\mathrm{N}}$ Silicon Drift Detector, Oxford, UK). The structures of La-S-As inclusions were identified by electron backscattered diffraction (EBSD, NordlysMax2, Oxford, UK). In addition, an electron probe microanalyzer (EPMA, JXA-8530F Plus, Tokyo, Japan) was used to measure the chemical compositions of La-S-As inclusions.

\section{Results and Discussion}

\subsection{Planar Mismatch Calculation of La-O-S-As Inclusions}

The RE-O-S-As inclusions mainly involve $\mathrm{RE}_{2} \mathrm{O}_{3}, \mathrm{RE}_{2} \mathrm{O}_{2} \mathrm{~S}$, RES, RE-S-As, RE-O-As, RE-As, as well as their complex. For arsenic ones, $\mathrm{LaAsO}_{4}$ and CeAs were identified [3,23], and La-S-As proved to be a solid solution of $\mathrm{LaS}$ and LaAs [25]. Arsenic inclusions are not the first ones that generate after adding rare earth, $\mathrm{RE}_{2} \mathrm{O}_{3}$, and $\mathrm{RE}_{2} \mathrm{O}_{2} \mathrm{~S}$ first form instead. Whether $\mathrm{RE}_{2} \mathrm{O}_{3}$ or $\mathrm{RE}_{2} \mathrm{O}_{2} \mathrm{~S}$ forms first depends on the initial content of oxygen and sulfur and their ratio. Heterogeneous nucleation plays a vital role in the subsequent generation of inclusions by decreasing the nucleation work.

According to the planar mismatch theory, when the mismatch of two planes is less than $6 \%$, heterogeneous nucleation takes place; when the mismatch is higher than $12 \%$, heterogeneous nucleation is less likely to happen. The planar mismatch can be calculated by Equation (1) [30].

$$
\delta_{(h k l)_{n}}^{(h k l)_{s}}=\frac{1}{3} \sum_{i=1}^{3}\left[\frac{\left|d_{[u v w]_{s}}^{i} \cos \theta-d_{[u v w]_{n}}^{i}\right|}{d_{[u v w]_{n}}^{i}}\right] \times 100
$$

where $\delta$ is the average of three mismatches between the planes $(h k l)_{s}$ and $(h k l)_{n}$; for each case, it is calculated along three low-index directions within a $90^{\circ}$ quadrant of the planes of the substrate and the nucleated solid. The interatomic spacing along $[u v w]_{s}$ and $[u v w]_{n}$ is in terms of $d_{[u v w] s}$ and $d_{[u v w] n \text {, }}$ respectively, nm. Low-index planes of the substrate and the nucleated solid are in terms of $(h k l)_{S}$ and $(h k l)_{n}$, respectively. Low-index directions in $(h k l)_{s}$ and $(h k l)_{n}$ are in terms of [uvw] and [uvw] $]_{n}$ respectively, and the angle between two corresponding directions is $\theta$, deg.

Taking the heterogeneous nucleation between the planes $\mathrm{La}_{2} \mathrm{O}_{3}(0001)$ and $\mathrm{La}_{2} \mathrm{O}_{2} \mathrm{~S}(0001)$ as an example, the schematic diagram of the mismatch is illustrated in Figure 1. The former is in red circles; the latter is in blue circles. The crystal parameters involved in the calculations are listed in Table 2 [31], and the calculation details are listed in Table 3. The mismatch between the two planes was calculated to be $2.76 \%$, indicating that $\mathrm{La}_{2} \mathrm{O}_{3}$ can be effective heterogeneous nucleation cores for the formation of $\mathrm{La}_{2} \mathrm{O}_{2} \mathrm{~S}$.

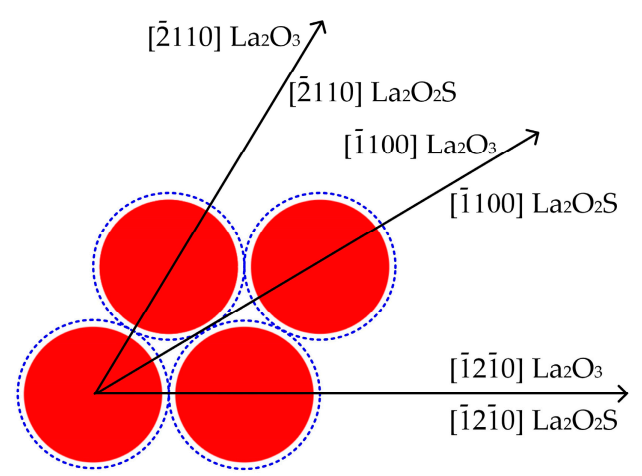

Figure 1. Crystallographic relationships of the planes $\mathrm{La}_{2} \mathrm{O}_{3}(0001)$ and $\mathrm{La}_{2} \mathrm{O}_{2} \mathrm{~S}(0001)$. 
Table 2. Crystallographic parameters of possible compounds of lanthanum and arsenic in steel.

\begin{tabular}{ccccc}
\hline \multirow{2}{*}{ Compounds } & Crystal System & \multicolumn{3}{c}{ Lattice Parameters $\left(\mathbf{2 5}{ }^{\circ} \mathbf{C}, \mathbf{n m}\right)$} \\
\cline { 3 - 5 } & & $\boldsymbol{a}_{\mathbf{0}}$ & $\boldsymbol{b}_{\mathbf{0}}$ & $\boldsymbol{c}_{\mathbf{0}}$ \\
\hline $\mathrm{La}_{2} \mathrm{O}_{3}$ & hexagonal & 0.3940 & - & 0.6127 \\
$\mathrm{La}_{2} \mathrm{O}_{2} \mathrm{~S}$ & hexagonal & 0.4052 & - & 0.6942 \\
$\mathrm{LaS}$ & cubic & 0.5854 & - & - \\
$\mathrm{LaAs}$ & cubic & 0.6158 & - & - \\
$\mathrm{LaAsO}_{4}$ & monoclinic & 0.6765 & 0.7218 & 0.8431 \\
\hline
\end{tabular}

Table 3. Calculation details of lattice between $\mathrm{La}_{2} \mathrm{O}_{3}$ and $\mathrm{La}_{2} \mathrm{O}_{2} \mathrm{~S}$ compounds.

\begin{tabular}{cccc}
\hline Interface & \multicolumn{3}{c}{$\mathbf{( 0 0 0 1 )} \mathbf{L a}_{\mathbf{2}} \mathbf{O}_{3} / /(\mathbf{0 0 0 1}) \mathbf{L a}_{\mathbf{2}} \mathbf{O}_{\mathbf{2}} \mathbf{S}$} \\
\hline$[h k l]_{s}$ & {$[\overline{1} 2 \overline{1} 0]$} & {$[\overline{1} 100]$} & {$[\overline{2} 110]$} \\
{$[h k l]_{n}$} & {$[\overline{1} 2 \overline{1} 0]$} & {$[\overline{1} 100]$} & {$[\overline{2} 110]$} \\
$d_{[h k l] s}$ & 0.3940 & 0.6824 & 0.3940 \\
$d_{[h k l] n}$ & 0.4052 & 0.7018 & 0.4052 \\
$\theta$ & 0 & 0 & 0 \\
$d_{[h k l] s \cdot \cos \theta}$ & 0.3940 & 0.6824 & 0.3940 \\
\hline$\delta(\%)$ & & 2.76 & \\
\hline
\end{tabular}

Table 4 lists the calculation results of the mismatches among $\mathrm{La}_{2} \mathrm{O}_{3}, \mathrm{La}_{2} \mathrm{O}_{2} \mathrm{~S}, \mathrm{LaS}$, and $\mathrm{LaAs}$ in the La-O-S-As system, and the calculation details are listed in Tables A1-A5 in the Appendix A. The results show that $\mathrm{La}_{2} \mathrm{O}_{3}$ can also provide effective heterogeneous nucleation cores for the generation of LaS with a mismatch of $4.82 \%$ except for that of $\mathrm{La}_{2} \mathrm{O}_{2} \mathrm{~S}$, and $\mathrm{La}_{2} \mathrm{O}_{2} \mathrm{~S}$ for that of $\mathrm{LaS}$ with a mismatch of $2.11 \%$, and $\mathrm{LaS}$ for that of $\mathrm{LaAs}$ with a mismatch of $4.94 \%$. Therefore, it is expected that $\mathrm{La}_{2} \mathrm{O}_{3}, \mathrm{La}_{2} \mathrm{O}_{2} \mathrm{~S}$, $\mathrm{LaS}$, and LaAs can serve as heterogeneous nucleation cores for the latter in turn.

Table 4. The calculated planar lattice misfits among crystal faces of La-O-S-As inclusions.

\begin{tabular}{ccc}
\hline Interface & $\boldsymbol{\delta} \mathbf{( \% )}$ & Effectiveness \\
\hline$(0001) \mathrm{La}_{2} \mathrm{O}_{3} / /(0001) \mathrm{La}_{2} \mathrm{O}_{2} \mathrm{~S}$ & 2.76 & Very effective \\
$(0001) \mathrm{La}_{2} \mathrm{O}_{3} / /(111) \mathrm{LaS}$ & 4.82 & Very effective \\
$(0001) \mathrm{La}_{2} \mathrm{O}_{3} / /(111) \mathrm{LaAs}$ & 9.52 & Moderately effective \\
$(0001) \mathrm{La}_{2} \mathrm{O}_{2} \mathrm{~S} / /(111) \mathrm{LaS}$ & 2.11 & Very effective \\
$(0001) \mathrm{La}_{2} \mathrm{O}_{2} \mathrm{~S} / /(111) \mathrm{LaAs}$ & 6.94 & Moderately effective \\
$(100) \mathrm{LaS}_{/} /(100) \mathrm{LaAs}$ & 4.94 & Very effective \\
\hline
\end{tabular}

As mentioned above, La-S-As inclusions can be considered as a solid solution of LaS and LaAs in a certain ratio, namely $x \mathrm{LaS}$. LaAs. Both LaS and LaAs have $\mathrm{NaCl}$-type cubic structures with a lattice constant difference of 5.2\%. The mismatch between LaS and LaAs can be used as a useful reference for whether LaS can provide effective heterogeneous nucleation cores for $x$ LaS.LaAs. The mismatch between LaS and LaAs was calculated to be $4.94 \%$, showing a high probability for LaS to serve as effective heterogeneous nucleation cores for $x \mathrm{LaS} \cdot \mathrm{LaAs}$.

We did not calculate the mismatch between $\mathrm{LaAsO}_{4}$ and other RE inclusions here for the very complicated structure of the former that is significantly different from the latter.

\subsection{Typical Arsenic Inclusions in Steel Ingot}

We found all the three expected arsenic inclusions in the ingot, namely La-S-As, $\mathrm{LaAsO}_{4}$, and La-As, as well as the complex containing them. Figure 2 shows the morphologies and compositions of a composite inclusion with an outer layer of La-S-As by EPMA. As shown in the figure, the core of the inclusion is La-O-S, next to a layer of LaS, and the outer layer is La-S-As. According to the stoichiometric ratio, it can be inferred that $20.6 \% \mathrm{O}$ at the core is used to generate $\mathrm{La}_{2} \mathrm{O}_{2} \mathrm{~S}$, consuming $20.6 \% \mathrm{La}$ and 
$10.3 \% \mathrm{~S}$ at the same time; the remaining La and $\mathrm{S}$ atomic ratios are $22.8 \%$ and $21.1 \%$, respectively, constituting LaS. Therefore, the composition of this composite inclusion is $\mathrm{La}_{2} \mathrm{O}_{2} \mathrm{~S}-\mathrm{LaS}-(\mathrm{La}-\mathrm{S}-\mathrm{As})$ from the inside out. Moreover, the ratio of LaS and LaAs constituting La-S-As is around 3:1, giving a high probability that the chemical formula of La-S-As is 3LaS.LaAs. Due to the similar outer electronic structure with As, P also reacted with $\mathrm{La}$, resulting in a small amount of LaP in the composite inclusions.

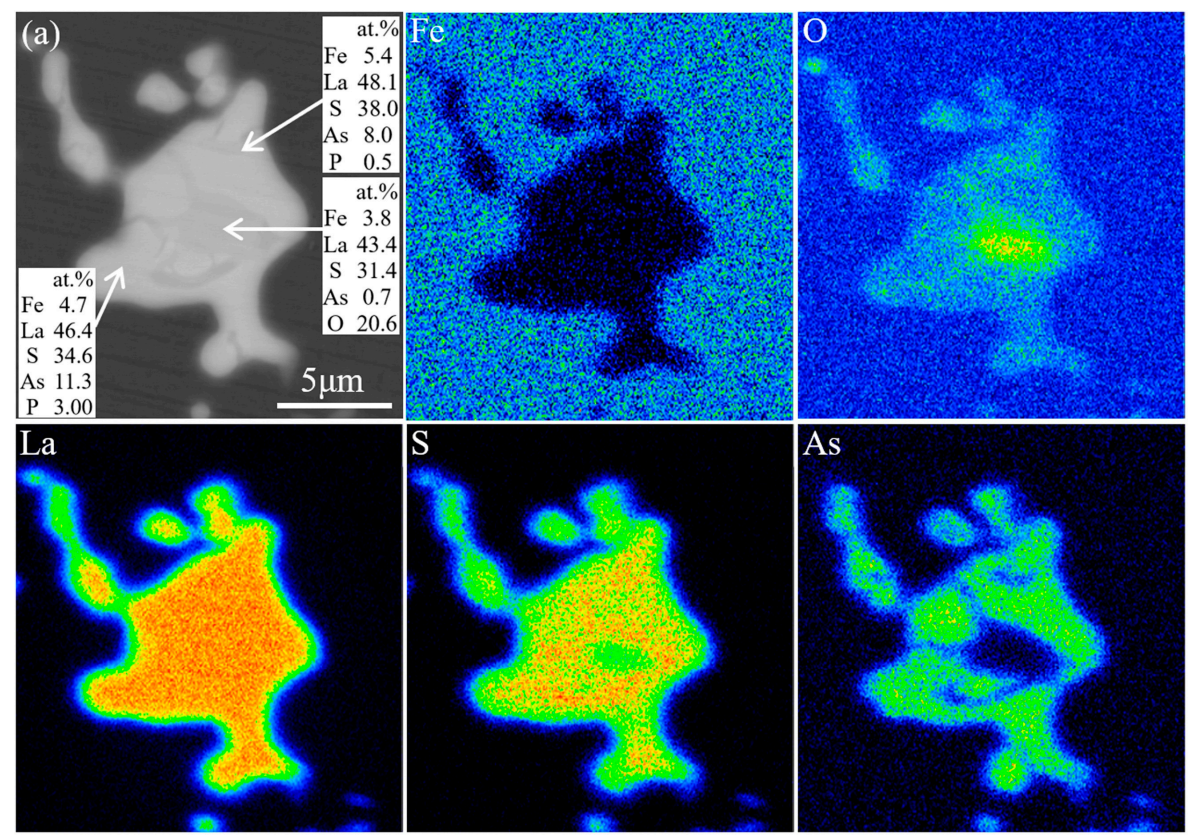

Figure 2. Morphologies and compositions of a $\mathrm{La}_{2} \mathrm{O}_{2} \mathrm{~S}-\mathrm{LaS}-(\mathrm{La}-\mathrm{S}-\mathrm{As})$ composite inclusion by electron probe microanalyzer (EPMA). (a) Backscattered electron (BSE) image of the inclusion.

A large amount of single-phase La-S-As inclusions with uniformly distributed atoms of La, S, and As were found around the $\mathrm{La}_{2} \mathrm{O}_{2} \mathrm{~S}-\mathrm{LaS}$-(La-S-As) composite inclusions, as shown in Figure 3. It turns out that they have a cubic structure (Figure 4), the same as LaS. Therefore, it is reasonable to infer that La-S-As inclusions exist in terms of a solid solution of LaS and LaAs. A small amount of $\mathrm{La}_{2} \mathrm{O}_{2} \mathrm{~S}$-LaS-(La-S-As) composite inclusions and a large number of La-S-As inclusions together constitute huge inclusion clusters of hundreds of microns or even millimeters, making it easy to remove them from molten steel. The formation mechanism will be discussed in Section 3.4.


Figure 3. Morphologies and composition distributions of La-S-As inclusions. (a) Secondary electron (SE) image and compositions of La-S-As inclusions. 


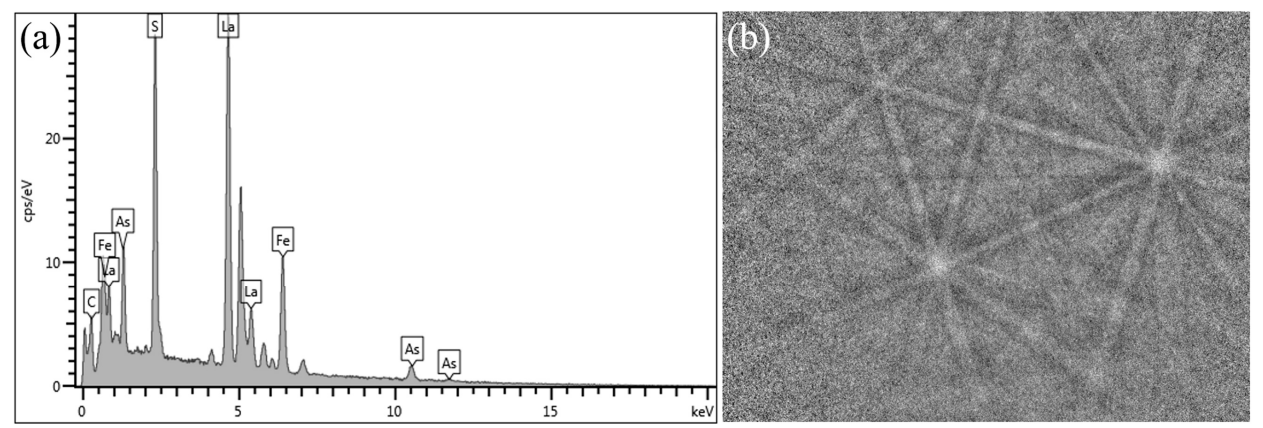

Figure 4. Chemical compositions and structure information of a typical La-S-As inclusion (point A in Figure 3). (a) Energy dispersive spectrum (EDS); (b) electron backscattered diffraction (EBSD) patterns.

Many inclusions with multiple layers were found, including $\mathrm{LaAsO}_{4}$, which we did not consider in the mismatch calculations. Figure 5 shows a $\mathrm{La}_{2} \mathrm{O}_{2} \mathrm{~S}-\mathrm{LaS}-(\mathrm{La}-\mathrm{S}-\mathrm{As})-\mathrm{LaAsO}_{4}$-(La-As) composite inclusion. Its core consists of minor $\mathrm{La}_{2} \mathrm{O}_{2} \mathrm{~S}$, major LaS, and a layer of La-S-As; the middle layer is mainly $\mathrm{LaAsO}_{4}$, and the thin outer layer is La-As. For the formation mechanism of these inclusions, we consider heterogeneous nucleation is not the only factor that works. Transformations of inclusions from one type to another may also take place during the solidification and cooling processes, which are mainly determined by the different solubility of $\mathrm{La}, \mathrm{O}, \mathrm{S}$, and As in the steel matrix with the decreasing temperature. For example, the outer part of a $\mathrm{La}_{2} \mathrm{O}_{3}$ inclusion can be transformed into $\mathrm{La}_{2} \mathrm{O}_{2} \mathrm{~S}$ with the increasing concentration of sulfur caused by solidification segregation. This is consistent with the theory based on the unreacted nuclear model. Once the transformations take place, the subsequent precipitation and growth of $\mathrm{La}_{2} \mathrm{O}_{2} \mathrm{~S}$ become easier.
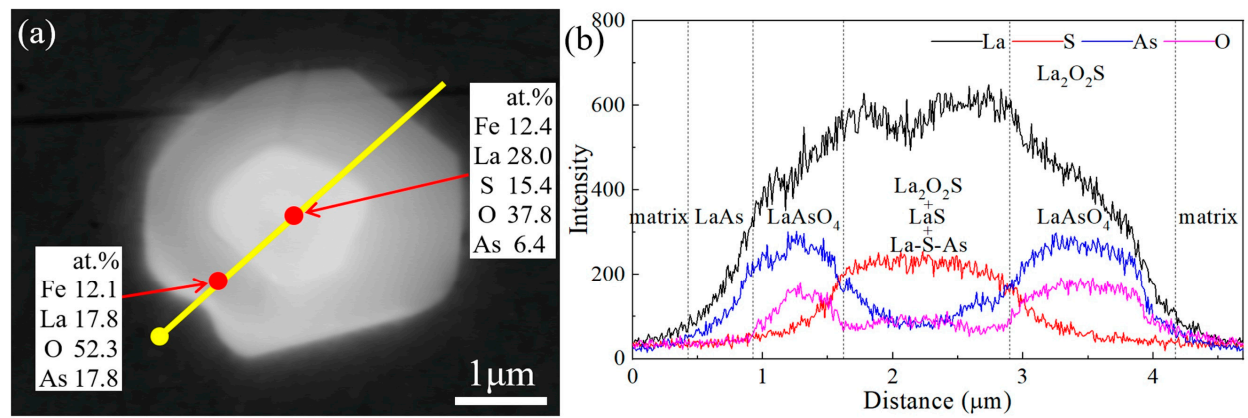

Figure 5. Morphologies and compositions of a $\mathrm{La}_{2} \mathrm{O}_{2} \mathrm{~S}-\mathrm{LaS}-(\mathrm{La}-\mathrm{S}-\mathrm{As})-\mathrm{LaAsO}_{4}$-(La-As) composite inclusion. (a) Backscattered electron (BSE) image and compositions; (b) line scanning patterns.

Figure 6 shows the morphologies and compositions of a (La-S-As)-(La-As) composite inclusion. As shown in the figure, there is no significant difference in color and phase boundaries between La-S-As and La-As, showing a high structural similarity of the two compounds.

We also found sporadic single-phase inclusions, La-S-As, $\mathrm{LaAsO}_{4}$, and La-As, that possibly generated during and after solidification due to segregation and the decreasing solute solubility in the steel matrix. They may also happen to be the outermost layers of the aforementioned composite inclusions that appear on the surface of the samples. This theory applies to all the observed inclusions. 

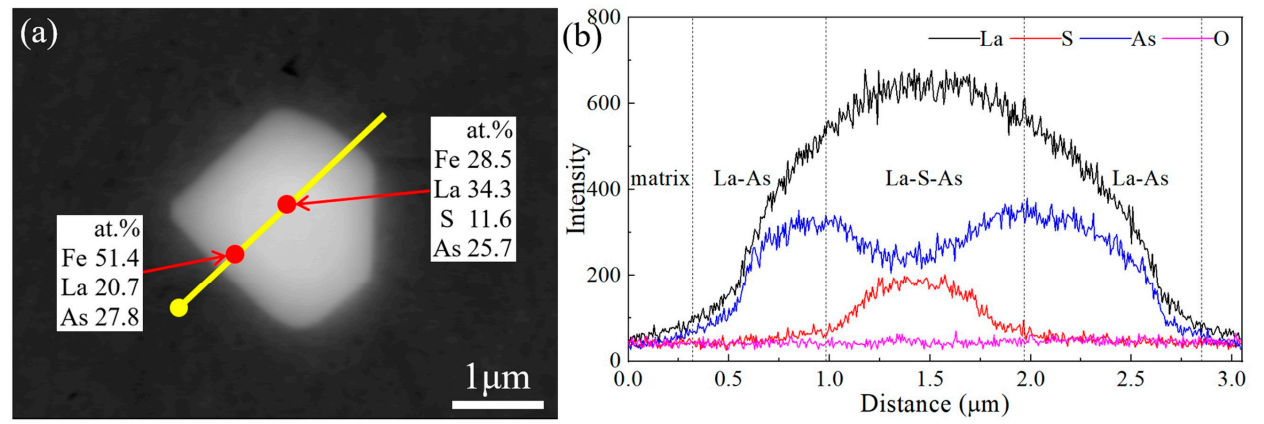

Figure 6. Morphologies and compositions of a (La-S-As)-(La-As) complex. (a) Backscattered electron (BSE) image and compositions of the inclusion; (b) line scanning patterns.

\subsection{Thermodynamic Calculation and Analysis}

The removal of arsenic from steel by adding rare earth can only be performed in the liquid steel, which mainly involves the formation and removal of La-S-As. It must be carefully considered that La-S-As forms after $\mathrm{La}_{2} \mathrm{O}_{3}$ and $\mathrm{La}_{2} \mathrm{O}_{2} \mathrm{~S}$. The thermodynamic data of inclusions in the La-O-S system are relatively abundant, although the data of various researchers are somewhat different. On the contrary, the thermodynamic data of RE-S-As are few. Only Li W et al. [32] reported Gibbs free energy of the reaction to form a hypothetical arsenic inclusion (CeS-CeAs) in steel, and Wu C et al. [29] mentioned Gibbs free energy of the formation of LaS.LaAs.

To analyze the factor affecting the formation of La-S-As in liquid steel, we assume that the chemical formula of La-S-As is LaS.LaAs for thermodynamic calculation first. Based on the activity model, regarding $1 \%$ dilute solution as a standard state, the stability diagram of La-O-S-As inclusions at $1600{ }^{\circ} \mathrm{C}$ was drawn according to Equations (2) to (6) [29,33,34], as shown in Figure 7. The activity coefficients used to calculate the activity of oxygen, sulfur, and lanthanum are the same as in previous work [23]. Under the initial composition conditions in this study, $\mathrm{La}_{2} \mathrm{O}_{3}$ generates first, and $\mathrm{La}_{2} \mathrm{O}_{2} \mathrm{~S}$ follows. Then, two possible paths of inclusion formation exist, as marked by blue and purple lines that are hypothetical and for illustration only. LaS, La-S-As, and LaAs form in turn if lanthanum and sulfur are sufficient; or no other inclusions form if the initial sulfur content is low, without considering the steel-refractory reactions here.

$$
\begin{gathered}
2[\mathrm{La}]+3[\mathrm{O}]=\mathrm{La}_{2} \mathrm{O}_{3}(\mathrm{~s}) \Delta G_{2}^{\mathrm{o}}=-1511520+379.2 T(\mathrm{~J} / \mathrm{mol}) \\
2[\mathrm{La}]+2[\mathrm{O}]+[\mathrm{S}]=\mathrm{La}_{2} \mathrm{O}_{2} \mathrm{~S}(\mathrm{~s}) \Delta G_{3}^{\mathrm{o}}=-1425820+351.0 T(\mathrm{~J} / \mathrm{mol}) \\
{[\mathrm{La}]+[\mathrm{S}]=\mathrm{LaS}(\mathrm{s}) \Delta G_{4}^{\mathrm{o}}=-490000+171.0 T(\mathrm{~J} / \mathrm{mol})} \\
{[\mathrm{La}]+[\mathrm{As}]=\mathrm{LaAs}(\mathrm{s}) \Delta G_{5}^{\mathrm{o}}=-355328.09+187.10 T(\mathrm{~J} / \mathrm{mol})} \\
2[\mathrm{La}]+[\mathrm{S}]+[\mathrm{As}]=\mathrm{LaS} \cdot \mathrm{LaAs}(\mathrm{s}) \Delta G_{6}^{\mathrm{o}}=-800553.1+322.78 T(\mathrm{~J} / \mathrm{mol})
\end{gathered}
$$

We also considered the probability of La directly reacting with As to form LaAs without generating $\mathrm{LaS}$ and La-S-As ahead. The activity product of La and As required to generate LaAs at $1600{ }^{\circ} \mathrm{C}$ was calculated to be 0.73 . However, the initial activity product of La and As in this work was calculated to be only 0.0038 , assuming both the activity coefficients of La and As equal to 1, as shown in Figure 8 . It is inferred that LaAs is less likely to form in molten steel at $1600{ }^{\circ} \mathrm{C}$. The activity of arsenic in molten steel under given compositions cannot be calculated at present for the lack of the thermodynamic data related to arsenic, especially the interaction coefficient of La and As. Setting both the activity coefficients of La and As to 1 deviates from the actual value to a large extent. 


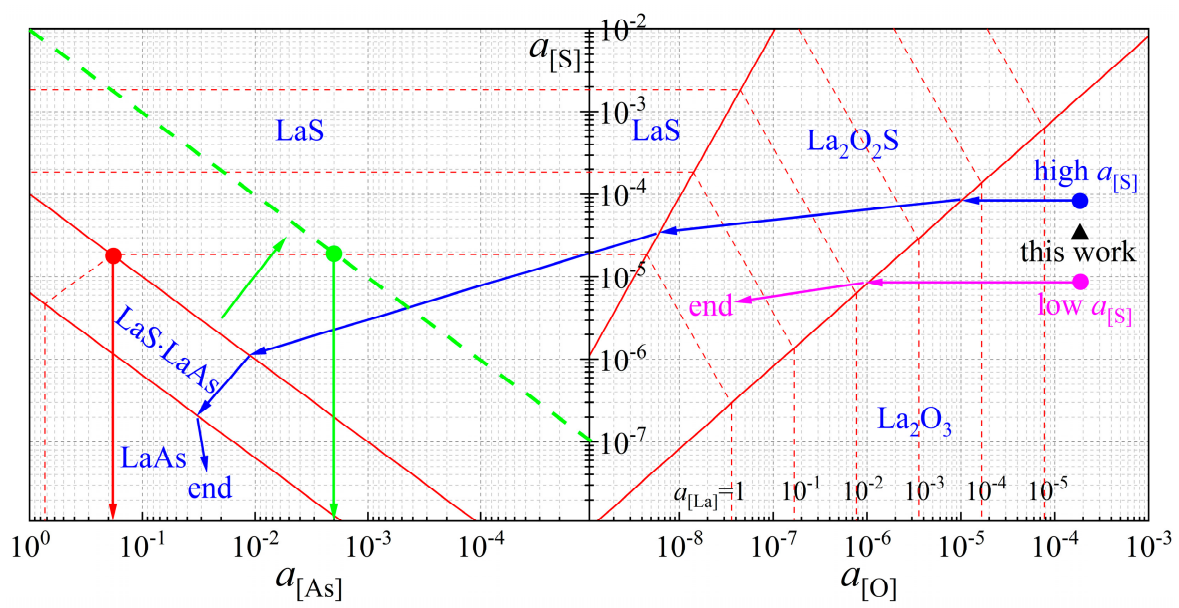

Figure 7. Stability of La-O-S-As inclusions at $1600{ }^{\circ} \mathrm{C}$.



Figure 8. Stability of LaAs inclusions under $1600{ }^{\circ} \mathrm{C}$.

Based on the aforementioned EPMA results, the ratio of LaS and LaAs is close to 3:1, far from assuming La-S-As is in terms of LaS.LaAs. Unfortunately, no identification of RE-S-As compounds in steel was carried out experimentally. The accuracy of the formula LaS.LaAs is questionable. On the contrary, if La-S-As is in terms of 3LaS.LaAs, it should form in the way of Equation (7). Its Gibbs free energy of formation is unknown, though. We can consider that it generates in the way of Equation (8), and $\Delta G_{8}^{o}$ should be negative and is equal to $\Delta G_{9}^{o}$ minus $\Delta G_{10}^{o}$. Equations (9) and (10) describe the boundaries of LaS-LaS.LaAs and LaS-3LaS.LaAs, respectively, and they have the same formula to calculate the equilibrium constants (Equation (11)). It can be obtained that $K_{9}$ is smaller than $K_{10}$ by comparing corresponding Gibbs free energy. Therefore, compared with the formation of LaS.LaAs, the equilibrium activity of arsenic becomes lower if 3LaS.LaAs forms instead under conditions of the same lanthanum and sulfur activity, beneficial to the formation of La-S-As and the removal of arsenic. This leads to the moving of the LaS-LaS.LaAs boundary to the green dotted line (the LaS-3LaS.LaAs boundary) shown in Figure 7.

$$
\begin{gathered}
4[\mathrm{La}]+3[\mathrm{~S}]+[\mathrm{As}]=3 \mathrm{LaS} \cdot \operatorname{LaAs}(\mathrm{s}) \Delta G_{7}^{\mathrm{o}}(\mathrm{J} / \mathrm{mol}) \\
\mathrm{LaS} \cdot \operatorname{LaAs}(\mathrm{s})+2 \mathrm{LaS}(\mathrm{s})=3 \mathrm{LaS} \cdot \operatorname{LaAs}(\mathrm{s}) \Delta G_{8}^{\mathrm{o}}(\mathrm{J} / \mathrm{mol}) \\
{[\mathrm{S}]+\mathrm{LaS} \cdot \operatorname{LaAs}(\mathrm{s})=2 \mathrm{LaS}(\mathrm{s})+[\mathrm{As}] \Delta G_{9}^{\mathrm{o}}=-179446.9+19.22 T(\mathrm{~J} / \mathrm{mol})} \\
{[\mathrm{S}]+3 \mathrm{LaS} \cdot \operatorname{LaAs}(\mathrm{s})=4 \mathrm{LaS}(\mathrm{s})+[\mathrm{As}] \Delta G_{10}^{\mathrm{o}}(\mathrm{J} / \mathrm{mol})}
\end{gathered}
$$




$$
K=\exp \left(-\Delta G^{\mathrm{o}} / R T\right)=a_{[\mathrm{As}]} / a_{[\mathrm{S}]}
$$

\subsection{Formation Mechanism of La-S-As in Molten Steel and its Distribution in the Ingot}

To investigate the formation mechanism of La-S-As, we carried out plenty of line scanning analysis. Figure 9 shows the morphologies and compositions of typical La-S-As-containing inclusions. $\mathrm{La}_{2} \mathrm{O}_{2} \mathrm{~S}$, $\mathrm{LaS}$, and LaAs, in turn, have mismatches of $2.11 \%$ and $4.94 \%$, making $\mathrm{La}_{2} \mathrm{O}_{2} \mathrm{~S}-\mathrm{LaS}-(\mathrm{La}-\mathrm{S}-\mathrm{As}$ ) composite inclusions easy to form.
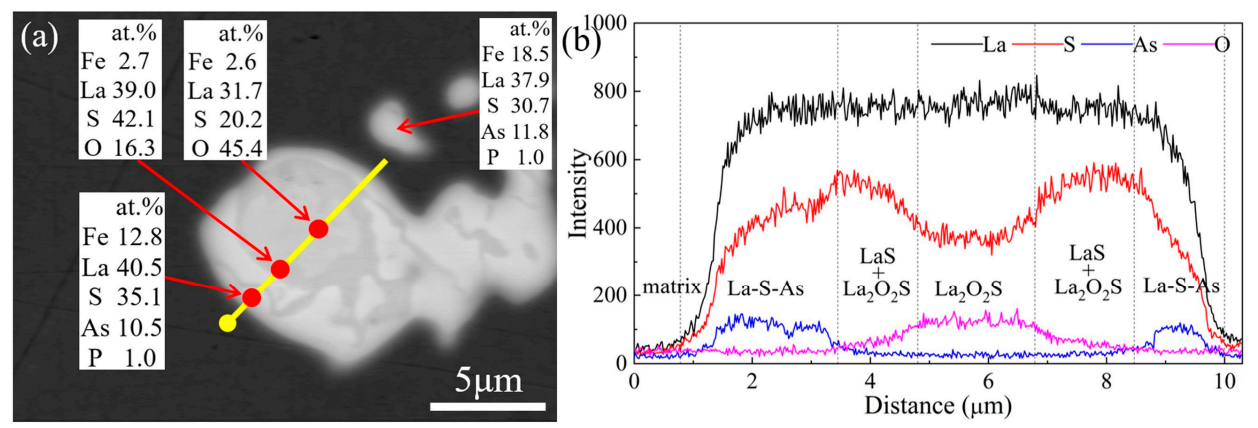

Figure 9. Morphologies and compositions of typical La-S-As-containing inclusions. (a) Backscattered electron (BSE) image and compositions; (b) line scanning patterns.

The essence of heterogeneous nucleation is one phase providing a substrate for another subsequently precipitating phase by reducing the nucleation work of the latter, thereby increasing the formation temperature of the latter. If La-S-As forms by homogeneous nucleation, its generation temperature will be relatively low; on the contrary, the existing LaS provides La-S-As with heterogeneous nucleation cores and reduces the supercooling required for the formation of the latter. In the same way, $\mathrm{La}_{2} \mathrm{O}_{2} \mathrm{~S}$ provides heterogeneous nucleation cores for the formation of LaS. As a result, the combined effect of $\mathrm{La}_{2} \mathrm{O}_{2} \mathrm{~S}$ and LaS significantly facilitates the generation of La-S-As. It is noted that sulfur plays a vital role in this process. If the content of sulfur is low, As will precipitate in the form of LaAs or $\mathrm{LaAsO}_{4}$ that was considered to be generated initially during solidification [3,23]. In that case, it is less likely to remove arsenic from steel.

Based on the thermodynamic analysis and the heterogeneous nucleation theory, three factors determine the removal of arsenic from molten steel by adding lanthanum.

First, the product of arsenic removal needs to have a high formation temperature. Gibbs free energy of the reaction to generate La-S-As is lower than that of LaAs, making the former the target product of arsenic removal.

Second, the pre-generated LaS serves as effective heterogeneous nucleation cores for the formation of La-S-As, which significantly reduces the nucleation work of the latter. A schematic diagram is used to describe the heterogeneous nucleation and growth of La-S-As, as shown in Figure 10. It is worth noting that the content of sulfur must be suitable. The high initial content of sulfur causes too much loss of rare earth, and the low initial content cannot produce LaS and La-S-As.

Third, La-S-As compounds tend to aggregate and grow into huge inclusion clusters, making it easy to remove them from molten steel. Two factors determine the separation of these inclusions from molten steel, as well as their distribution in the ingot. On the one hand, the density difference between inclusions and molten steel gives rise to a driving force that makes the inclusions float up to the surface of molten steel. The densities of $\mathrm{La}_{2} \mathrm{O}_{3}, \mathrm{La}_{2} \mathrm{O}_{2} \mathrm{~S}$, and $\mathrm{LaS}$ are $6.57,5.75$, and $5.66 \mathrm{~g} / \mathrm{cm}^{3}$, respectively; the density of La-S-As is expected to be between that of $\mathrm{LaS}$ and LaAs, which are 5.66 and $6.08 \mathrm{~g} / \mathrm{cm}^{3}$, respectively [31]. The density of molten steel is around $7.0 \mathrm{~g} / \mathrm{cm}^{3}$. Therefore, a buoyancy force caused by the density difference exists and drives these inclusions to float up. Single-phase La-S-As inclusions and the ones containing La-S-As with cores of $\mathrm{La}_{2} \mathrm{O}_{2} \mathrm{~S}$ and $\mathrm{LaS}$ are mostly distributed on top of the ingot. 


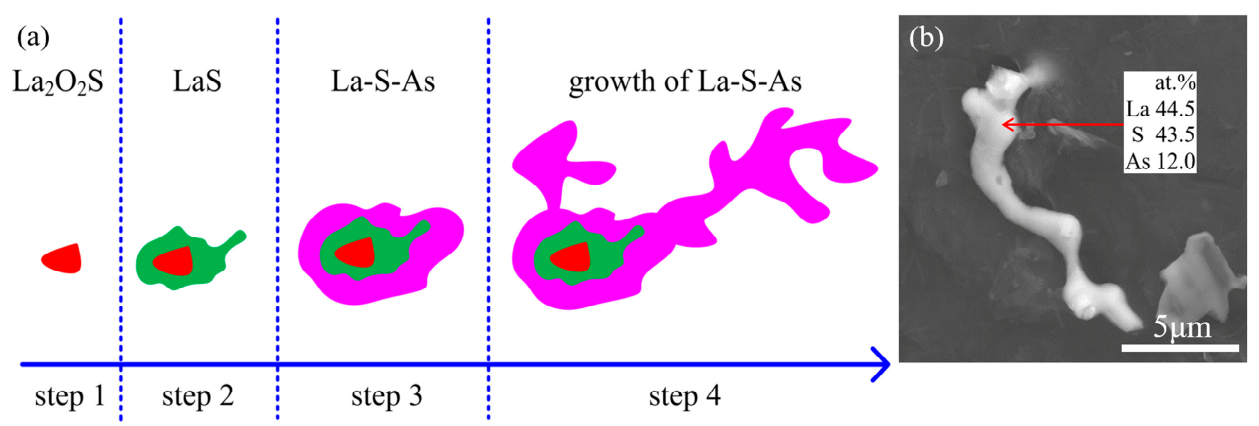

Figure 10. A schematic diagram of heterogeneous nucleation and growth of La-S-As inclusions. (a) The schematic diagram; (b) morphologies and compositions of La-S-As inclusions extracted from steel ingot by electrolysis.

On the other hand, the magnetic field of the induction furnace drives molten steel to flow, leading to the aggregation of inclusions, especially for La-S-As inclusions that become huge clusters with a size of hundreds of microns and a maximum of about $3 \mathrm{~mm}$ in this work. A larger size facilitates the removal of inclusions. These inclusion clusters either move to the surface of molten steel (Figure 11) or can be captured by the crucible wall, and the former is preferable. This is the reason why the arsenic concentration inside the ingot was dramatically lower than its average.

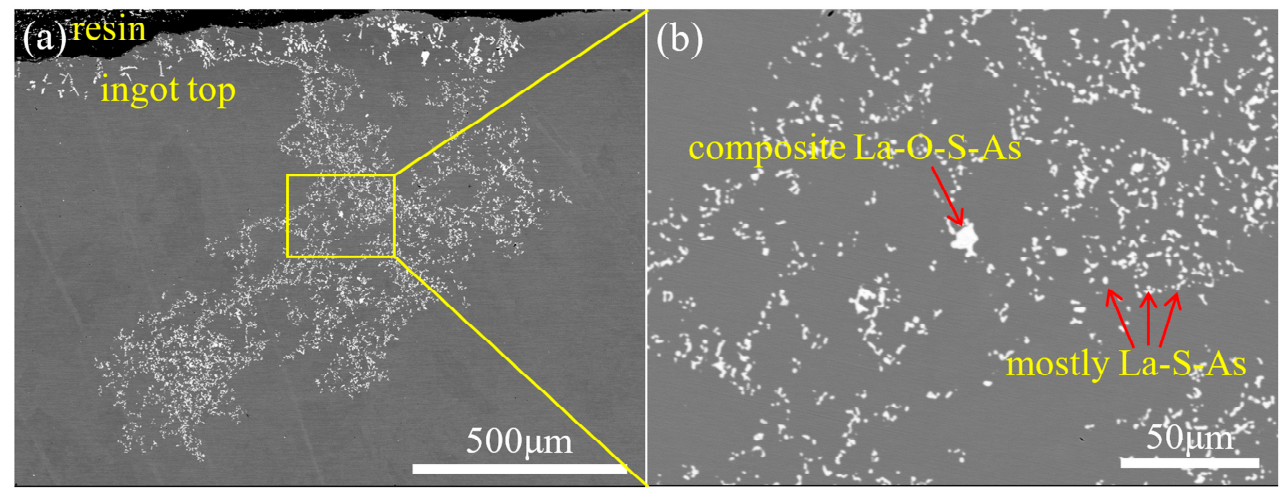

Figure 11. Morphologies of the inclusion clusters on the top of the ingot. (a) The whole map; (b) a local enlarged picture.

In this work, the arsenic content of the steel before lanthanum addition turned out to be $0.015 \%$, and it decreased to $0.010 \%$ in the ingot according to the results by ICP-OES. This proves that the formation of La-S-As achieves arsenic removal from molten steel. More details about its mechanism can be found in previous work [24].

During the solidification and cooling process, the inclusions remaining inside the ingot or resulting from the decrease in solute solubility provide heterogeneous nucleation cores for the precipitation of $\mathrm{LaAsO}_{4}$ and La-As, giving rise to a relatively uniform distribution. Their amount is far less than that distributed on the surface of the ingot.

In the industrial refining process, bottom-blowing argon can promote the aggregation and floatation of inclusions generated in molten steel, and molten slags can absorb these inclusions that dramatically decreases the chance for them to return into molten steel, thereby achieving the removal of arsenic.

\section{Conclusions}

The heterogeneous nucleation of arsenic inclusions in rare earth steel was investigated. A series of heterogeneous nucleation phenomena of inclusions in the La-O-S-As system was observed, which 
plays a vital role in removing arsenic from molten steel and also affects the precipitation of arsenic inclusions in solid steel. The heterogeneous nucleation of inclusions has a dramatic selectivity.

The sequences of heterogeneous nucleation of inclusions in the La-O-S-As system are $\mathrm{La}_{2} \mathrm{O}_{3}$, $\mathrm{La}_{2} \mathrm{O}_{2} \mathrm{~S}$, LaS, La-S-As, $\mathrm{LaAsO}_{4}$, and LaAs in turn. Sulfur plays a vital role in removing arsenic from molten steel though producing LaS and La-S-As; the former can serve as effective heterogeneous nucleation cores for the latter, thereby promoting the formation of the latter. The possible chemical formula of La-S-As proved to be 3LaS.LaAs.

La-S-As inclusions mainly exist in terms of clusters and are enriched on the surface of the ingot, owing to the density difference of the inclusions and molten steel. Controlling the initial sulfur content in an appropriate range is essential for the removal of arsenic from molten steel. The high initial content of sulfur causes too much loss of rare earth, and the low initial content cannot produce LaS and La-S-As.

Author Contributions: Conceptualization and methodology, H.W. and Y.W.; investigation and validation, H.W., P.Y., and S.J.; writing-review and editing, H.W.; funding acquisition, H.W. and Y.W. All authors have read and agreed to the published version of the manuscript.

Funding: This research was funded by the National Natural Science Foundation of China, grant number 51704051.

Acknowledgments: Many thanks to Chao Deng, from Electron Microscopy Center of Chongqing University, for his great help in the observation with SEM. We also thank Yang Zhou, from the Analytical and Testing Center of Chongqing University, for her great help in the identification of inclusions by EPMA.

Conflicts of Interest: The authors declare no conflict of interest.

\section{Appendix A}

Table A1. Calculated details of lattice between $\mathrm{La}_{2} \mathrm{O}_{3}$ and $\mathrm{LaS}$ compounds.

\begin{tabular}{|c|c|c|c|c|c|c|c|c|c|}
\hline \multirow{2}{*}{$\begin{array}{c}\text { Interface } \\
{[h k l]_{\mathrm{S}}}\end{array}$} & \multicolumn{3}{|c|}{$(0001) \mathrm{La}_{2} \mathrm{O}_{3} / /(100) \mathrm{LaS}$} & \multicolumn{3}{|c|}{$(0001) \mathrm{La}_{2} \mathrm{O}_{3} / /(110) \mathrm{LaS}$} & \multicolumn{3}{|c|}{$(0001) \mathrm{La}_{2} \mathrm{O}_{3} / /(111) \mathrm{LaS}$} \\
\hline & {$[\overline{1} 2 \overline{1} 0]$} & [1]100] & {$[\overline{2} 110]$} & {$[\overline{1} 2 \overline{1} 0]$} & {$[\overline{1} 100]$} & {$[\overline{2} 110]$} & {$[\overline{1} 2 \overline{1} 0]$} & {$[\overline{1} 100]$} & {$[\overline{2} 110]$} \\
\hline$[h k l]_{n}$ & [010] & [011] & [001] & {$[\overline{1} 10]$} & {$[\overline{1} 11]$} & {$[001]$} & [1]01] & {$[\overline{2} 11]$} & [1]10] \\
\hline$d_{[h k]_{s}}$ & 0.3940 & 0.6824 & 0.3939 & 0.3940 & 0.6824 & 0.3939 & 0.3940 & 0.6824 & 0.3939 \\
\hline$d_{[h k l] n}$ & 0.2927 & 0.4139 & 0.2927 & 0.4139 & 0.5070 & 0.2927 & 0.4139 & 0.7170 & 0.4139 \\
\hline$\theta$ & 0 & 15 & 30 & 0 & 5.26 & 30 & 0 & 0 & 0 \\
\hline$d_{[h k l]_{s}} \cdot \cos \theta$ & 0.3940 & 0.6591 & 0.3411 & 0.3940 & 0.6795 & 0.3411 & 0.3940 & 0.6824 & 0.3939 \\
\hline$\delta(\%)$ & & 36.80 & & & 18.46 & & & 4.82 & \\
\hline
\end{tabular}

Table A2. Calculated details of lattice between $\mathrm{La}_{2} \mathrm{O}_{3}$ and LaAs compounds.

\begin{tabular}{|c|c|c|c|c|c|c|c|c|c|}
\hline Interface & \multicolumn{3}{|c|}{$(0001) \mathrm{La}_{2} \mathrm{O}_{3} / /(100) \mathrm{LaAs}$} & \multicolumn{3}{|c|}{$(0001) \mathrm{La}_{2} \mathrm{O}_{3} / /(110) \mathrm{LaAs}$} & \multicolumn{3}{|c|}{$(0001) \mathrm{La}_{2} \mathrm{O}_{3} / /(111) \mathrm{LaAs}$} \\
\hline$[h k l]_{s}$ & {$[\overline{1} 2 \overline{1} 0]$} & {$[\overline{1} 100]$} & {$[\overline{2} 110]$} & {$[\overline{1} 2 \overline{1} 0]$} & {$[\overline{1} 100]$} & {$[\overline{2} 110]$} & {$[\overline{1} 2 \overline{1} 0]$} & [1]100] & {$[\overline{2} 110]$} \\
\hline$[h k l]_{n}$ & [010] & [011] & [001] & {$[\overline{1} 10]$} & {$[\overline{1} 11]$} & [001] & {$[\overline{1} 01]$} & {$[\overline{2} 11]$} & [1]10] \\
\hline$d_{[h k]_{s}}$ & 0.3940 & 0.6824 & 0.3939 & 0.3940 & 0.6824 & 0.3939 & 0.3940 & 0.6824 & 0.3939 \\
\hline$d_{[h k l] n}$ & 0.3079 & 0.4354 & 0.3079 & 0.4354 & 0.5333 & 0.3079 & 0.4354 & 0.7542 & 0.4354 \\
\hline$\theta$ & 0 & 15 & 30 & 0 & 5.26 & 30 & 0 & 0 & 0 \\
\hline$d_{[h k l]_{s}} \cdot \cos \theta$ & 0.3940 & 0.6591 & 0.3411 & 0.3923 & 0.5910 & 0.3939 & 0.3940 & 0.6824 & 0.3939 \\
\hline$\delta(\%)$ & \multicolumn{3}{|c|}{30.05} & \multicolumn{3}{|c|}{16.21} & \multicolumn{3}{|c|}{9.52} \\
\hline
\end{tabular}

Table A3. Calculated details of lattice between $\mathrm{La}_{2} \mathrm{O}_{2} \mathrm{~S}$ and $\mathrm{LaS}$ compounds.

\begin{tabular}{|c|c|c|c|c|c|c|c|c|c|}
\hline \multirow{2}{*}{$\begin{array}{c}\text { Interface } \\
{[h k l]_{S}}\end{array}$} & \multicolumn{3}{|c|}{$(0001) \mathrm{La}_{2} \mathrm{O}_{2} \mathrm{~S} / /(100) \mathrm{LaS}$} & \multicolumn{3}{|c|}{$(0001) \mathrm{La}_{2} \mathrm{O}_{2} \mathrm{~S} / /(110) \mathrm{LaS}$} & \multicolumn{3}{|c|}{$(0001) \mathrm{La}_{2} \mathrm{O}_{2} \mathrm{~S} / /(111) \mathrm{LaS}$} \\
\hline & {$[\overline{1} 2 \overline{1} 0]$} & {$[\overline{1} 100]$} & {$[\overline{2} 110]$} & {$[\overline{1} 2 \overline{1} 0]$} & {$[\overline{1} 100]$} & {$[\overline{2} 110]$} & {$[\overline{1} 2 \overline{1} 0]$} & {$[\overline{1} 100]$} & {$[\overline{2} 110]$} \\
\hline$[h k l]_{n}$ & [010] & [011] & [001] & {$[\overline{1} 10]$} & {$[\overline{1} 11]$} & [001] & {$[\overline{1} 01]$} & {$[\overline{2} 11]$} & [1]10] \\
\hline$d_{[h k]_{s}}$ & 0.4052 & 0.7018 & 0.4052 & 0.4052 & 0.7018 & 0.4052 & 0.4052 & 0.7018 & 0.4052 \\
\hline$d_{[h k l] n}$ & 0.2927 & 0.4139 & 0.2927 & 0.4139 & 0.5070 & 0.2927 & 0.4139 & 0.7170 & 0.4139 \\
\hline$\theta$ & 0 & 15 & 30 & 0 & 5.26 & 30 & 0 & 0 & 0 \\
\hline$d_{[h k l]_{s}} \cdot \cos \theta$ & 0.4052 & 0.6779 & 0.3509 & 0.4052 & 0.6988 & 0.3509 & 0.4052 & 0.7018 & 0.4052 \\
\hline$\delta(\%)$ & & 40.70 & & & 19.94 & & & 2.11 & \\
\hline
\end{tabular}


Table A4. Calculated details of lattice between $\mathrm{La}_{2} \mathrm{O}_{2} \mathrm{~S}$ and LaAs compounds.

\begin{tabular}{|c|c|c|c|c|c|c|c|c|c|}
\hline Interface & \multicolumn{3}{|c|}{$(0001) \mathrm{La}_{2} \mathrm{O}_{2} \mathrm{~S} / /(100) \mathrm{LaAs}$} & \multicolumn{3}{|c|}{$(0001) \mathrm{La}_{2} \mathrm{O}_{2} \mathrm{~S} / /(110) \mathrm{LaAs}$} & \multicolumn{3}{|c|}{$(0001) \mathrm{La}_{2} \mathrm{O}_{2} \mathrm{~S} / /(111) \mathrm{LaAs}$} \\
\hline$[h k l]_{s}$ & {$[\overline{1} 2 \overline{1} 0]$} & {$[\overline{1} 100]$} & {$[\overline{2} 110]$} & {$[\overline{1} 2 \overline{1} 0]$} & [1̄100] & {$[\overline{2} 110]$} & {$[\overline{1} 2 \overline{1} 0]$} & [1]100] & 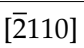 \\
\hline$[h k l]_{n}$ & [010] & [011] & [001] & {$[\overline{1} 10]$} & {$[\overline{1} 11]$} & [001] & {$[\overline{1} 01]$} & {$[\overline{2} 11]$} & {$[\overline{1} 10]$} \\
\hline$d_{[h k]_{s}}$ & 0.4052 & 0.7018 & 0.4052 & 0.4052 & 0.7018 & 0.4052 & 0.4052 & 0.7018 & 0.4052 \\
\hline$d_{[h k l] n}$ & 0.3079 & 0.4354 & 0.3079 & 0.4354 & 0.5333 & 0.3079 & 0.4354 & 0.7542 & 0.4354 \\
\hline$\theta$ & 0 & 15 & 30 & 0 & 5.26 & 30 & 0 & 0 & 0 \\
\hline$d_{[h k l]_{s}} \cdot \cos \theta$ & 0.4052 & 0.6779 & 0.3509 & 0.4035 & 0.6078 & 0.4052 & 0.4052 & 0.7018 & 0.4052 \\
\hline$\delta(\%)$ & \multicolumn{3}{|c|}{33.75} & \multicolumn{3}{|c|}{17.63} & \multicolumn{3}{|c|}{6.94} \\
\hline
\end{tabular}

Table A5. Calculated details of lattice between LaS and LaAs compounds.

\begin{tabular}{|c|c|c|c|c|c|c|c|c|c|}
\hline \multirow{2}{*}{$\begin{array}{c}\text { Interface } \\
{[h k l]_{\mathrm{s}}}\end{array}$} & \multicolumn{3}{|c|}{ (100) LaS//(100) LaAs } & \multicolumn{3}{|c|}{ (100) LaS//(110) LaAs } & \multicolumn{3}{|c|}{ (100) LaS//(111) LaAs } \\
\hline & [010] & {$[011]$} & [001] & [010] & {$[011]$} & [001] & [010] & [011] & [001] \\
\hline$[h k l]_{n}$ & [010] & {$[011]$} & {$[001]$} & {$[\overline{1} 10]$} & {$[\overline{1} 11]$} & [001] & {$[\overline{1} 01]$} & {$[\overline{2} 11]$} & {$[\overline{1} 10]$} \\
\hline$d_{[h k l] s}$ & 0.2927 & 0.4139 & 0.2927 & 0.2927 & 0.4139 & 0.2927 & 0.2927 & 0.4139 & 0.2927 \\
\hline$d_{[h k l] n}$ & 0.3079 & 0.4354 & 0.3079 & 0.4354 & 0.5333 & 0.3079 & 0.4354 & 0.7542 & 0.4354 \\
\hline$\theta$ & 0 & 0 & 0 & 0 & 0 & 0 & 0 & 0 & 0 \\
\hline$d_{[h k l] s} \cdot \cos \theta$ & 0.2927 & 0.4139 & 0.2927 & 0.2927 & 0.4139 & 0.2927 & 0.2927 & 0.4139 & 0.2927 \\
\hline$\delta(\%)$ & \multicolumn{3}{|c|}{4.94} & \multicolumn{3}{|c|}{20.03} & \multicolumn{3}{|c|}{36.89} \\
\hline
\end{tabular}

\section{References}

1. Xin, W.; Song, B.; Huang, C.; Song, M.; Song, G. Effect of arsenic content and quenching temperature on solidification microstructure and arsenic distribution in iron-arsenic alloys. Int. J. Miner. Metall. Mater. 2015, 22, 704-713. [CrossRef]

2. Xin, W.; Zhang, J.; Jiang, Y.; Deng, Y.; Meng, Q.; Song, B. Effect of rare earth Ce on the isothermal oxidation behavior in air of arsenic bearing steels. Metall. Res. Technol. 2019, 116, 415. [CrossRef]

3. Xin, W.; Song, B.; Song, M.; Song, G. Effect of cerium on characteristic of inclusions and grain boundary segregation of arsenic in iron melts. Steel Res. Int. 2015, 86, 1430-1438. [CrossRef]

4. Wang, H.; Bai, B.; Jiang, S.; Sun, L.; Wang, Y. An in situ study of the formation of rare earth inclusions in arsenic high carbon steels. ISIJ Int. 2019, 59, 1259-1265. [CrossRef]

5. Xin, W.; Zhang, J.; Luo, G.; Wang, R.; Meng, Q.; Song, B. Improvement of hot ductility of C-Mn steel containing arsenic by rare earth Ce. Metall. Res. Technol. 2018, 115, 419. [CrossRef]

6. Zhu, D.; Fang, J. Investigation on the current status of harmful elements in high-quality alloy steel. In The Influence and Control of Impurity Elements Tin, Arsenic, Antimony, Lead and Bismuth on the Quality of Alloy Structural Steel; Central Iron \& Steel Research Institute: Beijing, China, 1994; pp. 12-21.

7. Pauliuk, S.; Wang, T.; Müller, D.B. Moving toward the circular economy: The role of stocks in the Chinese steel cycle. Environ. Sci. Technol. 2011, 46, 148-154. [CrossRef]

8. Björkman, B.; Samuelsson, C. Recycling of steel. In Handbook of Recycling; Elsevier: Oxford, UK, 2014; pp. 65-83.

9. Lv, Q.; Zhang, S.; Hu, X. Experimental study on removal arsenic in iron ore with arsenic sintering process. Iron Steel 2010, 45, 7-11.

10. Jiang, M.; Sun, T.; Qin, X.; Ji, Y.; Wang, Z. Study on removing arsenic and tin from As-Sn bearing iron concentrates by direct reduction roasting of coal. Min. Metall. Eng. 2011, 31, 86-89.

11. Wang, L.; Haichuan, W.; Xu, F.; Chen, P. Experimental study of microwave treating high arsenic ore. Metall. Eng. 2015, 2, 29-35. [CrossRef]

12. Nakamura, Y.; Tokumitsu, N.; Harashima, K.; Segawa, K. Refining of $18 \% \mathrm{Cr}-8 \%$ Ni steel with $\mathrm{Ca}-\mathrm{CaF} 2$ solution. Trans. ISIJ 1976, 16, 623-627. [CrossRef]

13. Kitamura, K.; Takenouchi, T.; Iwanami, Y. Removal of impurities from molten steel by $\mathrm{CaC}_{2}$. Tetsu-to-Hagané 1985, 71, 220-227. [CrossRef] 
14. Li, W.; Bao, Y.; Wang, M.; Lin, L. Experimental study on dearsenization of molten steel with different Ca alloy. Chin. J. Eng. 2016, 38, 484-493.

15. Fu, B.; Xue, Z.; Wu, G.; Wu, L.; Wu, Y.; Ke, C. Experimental study on the dearsenization of hot metal with $\mathrm{CaC}_{2}-\mathrm{CaF}_{2}$ slag. Chin. J. Proc. Eng. 2010, 10, 146-149.

16. Dong, Y.; Shi, Z.; Zhang, L.; Peng, Y.; Hong, Y. Study on dearsenization of molten iron. Iron Steel 1984, 19, 1-7.

17. Chang, L.; Shi, X.; Wang, J.; Zhou, L.; Luo, L. Research on dearsenication by reduction process in hot metal. Iron Steel Vanadium Titan. 2014, 35, 113-117.

18. Huang, C.; Song, B.; Xin, W.; Jia, S.; Yang, Y. Influence of rare earth La on hot ductility of low carbon steel containing As and Sn. Heat Treat. Met. 2015, 40, 1-6.

19. Vahed, A.; Kay, D.A.R. Thermodynamics of rare earths in steelmaking. Metall. Trans. B 1976, 7, $375-383$. [CrossRef]

20. Lu, W.K.; McLean, A. Thermodynamic behaviour of rare-earth elements in molten steel. Ironmak. Steelmak. 1974, 1, 228-233.

21. Han, Q.; Dong, Y.; Feng, X.; Xiang, C.; Yang, S. Equilibria between rare earth elements and sulfur in molten iron. Metall. Mater. Trans. B 1985, 16, 785-792. [CrossRef]

22. Katsumata, A.; Todoroki, H. Effect of rare earth metal on inclusion composition in molten stainless steel. Iron Steelmak. 2002, 29, 51-57.

23. Wang, H.; Xiong, L.; Zhang, L.; Wang, Y.; Shu, Y.; Zhou, Y. Investigation of RE-O-S-As inclusions in high carbon steels. Metall. Mater. Trans. B 2017, 48, 2849-2858. [CrossRef]

24. Wang, H.; Yu, P.; Jiang, S.; Bai, B.; Sun, L.; Wang, Y. Evolution of inclusions in steelmaking process of rare earth steels containing arsenic with alumina crucibles. Metals 2020, 10, 275. [CrossRef]

25. Wang, H.; Jiang, S.; Yu, P.; Bai, B.; Sun, L.; Wang, Y. Distribution of arsenic inclusions in rare earth steel ingots. Metals 2020, 10, 146. [CrossRef]

26. Zhang, J.; Dou, S. Study on interaction between cerium and arsenic. Adv. Mater. Res. 2011, 194, 1231-1234. [CrossRef]

27. Wang, L.; Lin, Q.; Ji, J.; Lan, D. New study concerning development of application of rare earth metals in steels. J. Alloy. Compd. 2006, 384-386. [CrossRef]

28. Li, Y.; Sun, M.; Jiang, Z.; Chen, C.; Chen, K.; Huang, X.; Sun, S.; Li, H. Inclusion modification in C104Cr saw wire steel with different cerium content. Metals 2019, 9, 54. [CrossRef]

29. Wu, C.; Cheng, G.; Tian, J.; Xie, Y. Effect of rare earths on 09Cr2AlMoRE steel with residual elements arsenic and tin. J. Chin. Soc. Rare Earths 2013, 31, 597-604.

30. Bramfitt, B.L. The effect of carbide and nitride additions on the heterogeneous nucleation behavior of liquid iron. Metall. Trans. 1970, 1, 1987-1995. [CrossRef]

31. Villars, P. Pauling file. In Inorganic Solid Phases, SpringerMaterials (Online Database); Springer: Heidelberg, Germany, 2012.

32. Li, W.; Liu, Q.; Ye, W.; Zhang, C. Kinetics of rare-earth on the low carbon steel containing arsenic. Chin. J. Eng. 1983, 61-67.

33. Hino, M.; Ito, K. Thermodynamic Data for Steelmaking; Tohoku University Press: Sendai, Japan, 2010; pp. 249-257.

34. Wang, L.; Du, T. Study on equilibrium of [La]-[S]-[O] system in steel. Rare Earth 1986, 2, 25-32.

(C) 2020 by the authors. Licensee MDPI, Basel, Switzerland. This article is an open access article distributed under the terms and conditions of the Creative Commons Attribution (CC BY) license (http://creativecommons.org/licenses/by/4.0/). 